\title{
Naturally Occurring Variation in Vasopressin Immunoreactivity Is Associated with Maternal Behavior in Female Peromyscus Mice
}

\author{
Janet K. Bester-Meredith ${ }^{\mathrm{a}}$ Catherine A. Marler ${ }^{\mathrm{b}}$ \\ ${ }^{a}$ Department of Biology, Seattle Pacific University, Seattle, Wash., and b Departments of Psychology and Zoology, \\ University of Wisconsin-Madison, Madison, Wisc., USA
}

\section{Key Words}

Amygdala $\cdot$ Bed nucleus of the stria terminalis • Cross-fostering $\cdot$ Maternal behavior $\cdot$ Peromyscus . Vasopressin

\begin{abstract}
In many mammals, species-appropriate social behavior is necessary for an individual's ability to survive and reproduce. In the present study, we examined whether argininevasopressin (AVP) pathways that have been associated with social behavior differed between two closely related species of Peromyscus mice with different patterns of maternal behavior. We also tested whether individual levels of AVP-immunoreactive staining (AVP-ir) were associated with individual levels of maternal behavior as measured using a composite score consisting of huddling, nursing, grooming and time spent inside the nest (HNGI score). In addition, we examined whether these associations between vasopressin and behavior differed between species. Females from the highly biparental species, California mice, displayed higher AVP-ir in the bed nucleus of the stria terminalis (BNST), which corresponded with a higher level of nest building and a higher HNGI score than was found in the less parental white-footed mice. The HNGI score was positively associated with AVP-ir in the medial amygdala in female California mice but not
\end{abstract}

\section{KARGER}

Fax +4161306 1234

E-Mail karger@karger.ch

www.karger.com
(C) 2012 S. Karger AG, Basel

0006-8977/12/0804-0244\$38.00/0

Accessible online at:

www.karger.com/bbe white-footed mice. Finally, we examined whether AVP-ir in these pathways varied based on the species-specific rearing environments by reciprocally cross-fostering California mice and white-footed mice. In contrast to previous research with male California mice, cross-fostering itself had no effect on maternal behavior or any consistent effect on AVP-ir staining in brain areas such as the BNST and associated brain areas. This suggests that there is little plasticity in maternal behavior and that the underlying AVP system in females does not respond to the postnatal environment provided by the parents. The positive associations between maternal behavior and AVP-ir indicate that AVP may regulate maternal behavior despite the lack of plasticity in AVP and maternal behavior.

Copyright $\odot 2012$ S. Karger AG, Basel

\section{Introduction}

The neuropeptides arginine vasopressin (AVP) and oxytocin are members of a neuropeptide family with a long evolutionary lineage that has been associated with social behavior [Keverne and Curley, 2004]. This neuropeptide family may be especially important in regulating social behavior in mammals where variation in behavior among closely related species leads to interspecific variation in social and mating systems. Flexibility in vaso- 
pressinergic pathways within a single individual allows for individuals to respond to changes within their social environments and to respond appropriately to hormonal and social cues depending on an individual's reproductive status.

So far, few comparisons have been made across species regarding AVP regulation of female social behavior. In the current study, we examine whether there exists a species difference in AVP that is associated with differences in maternal behavior. Additionally, although male rodents tend to show flexibility in the amount of AVP expressed in response to hormonal or social cues [e.g. Bester-Meredith and Marler, 2003a; Beiderbeck et al., 2007], less is known about the flexibility of this pathway in female rodents. The role of AVP in regulating female parental behaviors also has been less well studied because the hormonal changes during pregnancy and lactation have been assumed to regulate female reproductive and social behaviors in their entirety. Vasopressin has traditionally been implicated in indirect control of maternal behavior by regulating water balance during lactation in response to the osmoregulatory challenge of licking and grooming pups [review by Caldwell et al., 2008]. Similarly, prolactin, a hormone involved in parturition and lactation, promotes release of vasopressin from brain areas involved in osmoregulation, such as the paraventricular nucleus and the supraoptic nucleus [Vega et al., 2010]. However, only recently, more direct effects of AVP on other forms of maternal behavior in laboratory mice and rats have been demonstrated. In a strain of low-anxiety laboratory mice, intracerebroventricular injections of AVP facilitated pup retrievals [Kessler et al., 2011]. In contrast, intracerebroventricular injections of both AVP and V1a antagonist injections decreased a composite score of maternal behavior in rats during maternal aggression trials [Nephew and Bridges, 2008a]. Moreover, AVP receptor antagonists injected into the medial amygdala impair maternal memory [Nephew and Bridges, 2008b] implicating the medial amygdala as an interesting brain area for species comparisons, especially because of other research linking AVP and memory [Dantzer et al., 1988; Engelmann and Landgraf, 1994; Lukas et al., 2011]. However, none of these studies have examined the role of AVP in regulating female parental care in a biparental species where AVP may be important in regulating male parental care.

We proposed to examine the association between maternal behavior and levels of the AVP peptide in Peromyscus californicus (California mice) because of the above findings, as well as a previously established positive as- sociation between paternal behavior and AVP-immunoreactive staining (AVP-ir) in this species [Bester-Meredith and Marler, 2003a] and in voles [Wang et al., 1994; Parker and Lee, 2001]. The California mouse is a monogamous species in which males and females provide extensive parental care toward offspring [Gubernick and Alberts, 1987, 1989; Ribble, 1991; Gubernick et al., 1993; Bester-Meredith et al., 1999; Gubernick and Teferi, 2000; Trainor and Marler, 2001; Bester-Meredith and Marler, 2003a]. The white-footed mouse provides an interesting comparison because it is a promiscuous species in which males and females express less parental behavior than the California mouse [Schug et al., 1992; Bester-Meredith et al., 1999; Bester-Meredith and Marler, 2003a].

To examine whether the social environment during development alters either adult maternal behavior or AVP-ir of offspring, we cross-fostered mouse pups between the two species in the current study. Using this same cross-fostering technique, we previously demonstrated that unmated male California mice raised by white-footed mice experience a decrease in resident-intruder aggression accompanied by a decrease in AVP-ir staining in the bed nucleus of the stria terminalis (BNST) [Bester-Meredith and Marler, 2001]. Paternal behavior is also altered such that male California mice raised by white-footed mice and exposed to fewer pup retrievals in turn display fewer retrievals of their biological offspring [Bester-Meredith and Marler 2003a]. Similar to males, female California mice also show decreased aggression in response to cross-fostering, although their behavioral changes were observed only in the neutral arena [BesterMeredith and Marler, 2007]. We used the same behavioral paradigm here, but instead focused on maternal behavior. We worked with cross-fostered (fostered between species), in-fostered (fostered to parents of their biological species) and control animals (raised by their biological parents). All behavioral and AVP-ir measurements described below were made on adult females raised by foster parents (or controls) and then paired with males from the same species and treatment condition. We focused on AVP-ir staining in the BNST and medial amygdala, brain areas in which AVP has been associated with social behavior, including paternal care and aggression [Wang, 1995; Ferris et al., 1997; Bester-Meredith et al., 1999; BesterMeredith and Marler, 2001]. Further support for the role of the BNST in maternal behavior has been found through the study of other neurochemical pathways within the BNST in a variety of species [Mann and Bridges, 2002; Ruscio and Adkins-Regan, 2004; Gonzalez-Mariscal et al., 2005; reviewed by Bosch and Neumann, 2012]. We also 
Table 1. Timeline for data collection in Peromyscus mice

\begin{tabular}{|c|c|c|c|c|}
\hline Month 1 & Month 10 & Month 14 & Month 15 & Month 16 \\
\hline Females born & $\begin{array}{l}\text { Females in } \\
\text { aggression tests }\end{array}$ & Pairing of females & $\begin{array}{l}\text { Birth of } \\
\text { litter No. } 1\end{array}$ & $\begin{array}{l}\text { Birth of } \\
\text { litter No. } 2\end{array}$ \\
\hline $\begin{array}{l}\text { Females were raised as } \\
\text { cross-fostered, in-fostered } \\
\text { or control mice } \\
\text { (see text for description) }\end{array}$ & $\begin{array}{l}\text { Data were previously } \\
\text { reported in Bester- } \\
\text { Meredith and Marler } \\
\text { [2007] }\end{array}$ & $\begin{array}{l}\text { Females were paired with } \\
\text { males from the same species } \\
\text { and treatment condition }\end{array}$ & $\begin{array}{l}\text { Measurements of maternal } \\
\text { behavior in females housed } \\
\text { with mate and pups }\end{array}$ & $\begin{array}{l}\text { Females sacrificed } \\
\text { on day } 3 \text { after the } \\
\text { birth of pups }\end{array}$ \\
\hline
\end{tabular}

measured AVP-ir in the paraventricular nucleus of the hypothalamus and supraoptic nucleus, brain areas that have been linked to lactation and maternal care [reviewed by Bosch and Neumann, 2012] in addition to their previously recognized roles in stress, osmoregulation and other non-reproductive functions [Wotjak et al., 1996; Ma et al., 1999; Scott and Brown, 2010]. Measurements were not made in the lateral septum or the medial preoptic area because staining was too light to be quantifiable.

\section{Materials and Methods}

\section{Subjects and Housing}

We used females from 22 litters of white-footed mice and 27 litters of California mice. These females were reared in a laboratory colony at the University of Wisconsin, Madison, and were descendents of wild-caught animals. The animals were maintained under a 14:10 light-dark cycle with lights on at 04:00. Cross-fostered, in-fostered and control females were used in this study (described below and in table 1). During maternal care observations (described in more detail below), all animals were housed in clear polycarbonate observation chambers. Two small chambers $(22 \times 14.5 \times 30 \mathrm{~cm}$ each $)$ were separated by a removable, clear Plexiglas partition, each opening into a third, larger chamber $(30 \times 29 \times 30 \mathrm{~cm})$ containing a running wheel, ad libitum Purina 5015 mouse chow and a water bottle. To standardize the methodology between the species, females were mated during the postpartum estrus and housed with pups during lactation until weaning on day 25. After weaning, on the 3rd day after the birth of a second litter of offspring, females were housed with their mates in standard cages (white-footed mice: $29.2 \times 19.0 \times$ $12.7 \mathrm{~cm}$; California mice: $48.3 \times 26.7 \times 15.6 \mathrm{~cm}$ ) with cage floors covered by aspen shavings. Although standard cages differed due to species differences in body size (white-footed mice: $25 \mathrm{~g}$; California mice: $47 \mathrm{~g}$ ), housing did not differ between treatment groups within each species that were compared (i.e. cross-fostered and in-fostered or colony control females of the same species). Animals were maintained in accordance with the recommendations of the National Institutes of Health Guide for the Care and Use of Laboratory Animals with all research protocols approved by the Institutional Animal Care and Use Committee.

\section{Species Differences in Maternal Behavior}

To examine species differences in maternal behavior, parents and pups (all groups) were videotaped on alternate evenings from postpartum days 3 to 23 for $20 \mathrm{~min}$, at least $0.5 \mathrm{~h}$ after the onset of the dark cycle. Parents interact more with pups during early evening than any other time [unpubl. obs.]. Sample sizes for associations between maternal behavior and AVP-ir were smaller because AVP-ir was examined in a subset of these mice (described below). Videotapes were analyzed using the timer on the video recorder to determine durations of huddling with pups, nursing, retrieving pups, grooming pups, nest-building, and the amount of time spent inside of the nest (HNGI) by each parent [BesterMeredith and Marler, 2003b]. The onset and offset of each behavior by each parent was recorded through continuous observation. Because more than one behavior per parent could occur simultaneously, each taping session was analyzed repeatedly using continuous observation until the durations of all variables for both parents were recorded. For the present study, we sampled the taping sessions from days 5, 9, 13, 17 and 21 after the birth of pups. We substituted the average of the measured behaviors of the female during the otherwise unused taping sessions that occurred 2 days prior or after the intended taping session when the taping session was improperly recorded (15 of 265 taping sessions). For example, if day 13 was unusable, we substituted the average of days 11 and 15. Examination of similar behavioral data recorded on the parents of the mice used in the current study indicated that although parental behavior gradually shifted over the course of pup development, consecutive days did not differ significantly from one another [Bester-Meredith and Marler, unpubl. data].

\section{Cross-Fostering and Maternal Behavior}

The mothers used in this study were part of a larger study examining the effects of cross-fostering on parental behavior and aggression. Methods have been described in detail in Bester-Meredith and Marler [2001, 2003, 2007]. Within 36 h of birth, entire litters from each species were separated from their parents, wiped clean with water-soaked cotton balls and dipped in soiled bedding of their foster parents to enhance acceptance of pups from another species. Of these litters, 2 California mouse pups or 4 white-footed mouse pups from the same litter were exchanged to be raised by parents of the other species (cross-fostered) or to be raised by parents from their own species (in-fostered) that also had given birth within the last $36 \mathrm{~h}$. In-fostering was used to control for any behavioral changes due to separation from biological 
parents and being raised by foster parents. Animals from the general colony provided additional controls because cross-fostering and in-fostering were not done simultaneously due to limitations in the number of individuals available for fostering at any one time.

We investigated whether changes in the social environment lead to flexibility in the expression of maternal behavior by examining the effects of cross-fostering on maternal behavior in a random subset of the females described above using adult females from 9 litters each of control white-footed mice, California mice raised by white-footed mice (cross-fostered California mice), control California mice and in-fostered California mice (in-fostered California mice) and 8 litters of white-footed mice raised by California mice (cross-fostered white-footed mice). Previous research has demonstrated that the behavior of Peromyscus fathers is not affected by pup species [Bester-Meredith and Marler, 2003a] and there are few changes in the mothers in response to pup species [Bester-Meredith and Marler, unpubl. data]. Maternal behavioral data were obtained for 1 female per litter with the following exceptions: an additional female sibling per litter was paired with a male and the resulting data from siblings were averaged for all statistical analyses for 1 litter of in-fostered California mice, 2 litters of cross-fostered white-footed mice and 1 litter of control white-footed mice leading to the final litter sample sizes described above. Only 5 litters of in-fostered white-footed mice were used because only 5 of 14 pairs of in-fostered white-footed mice bred successfully. Although this was a low rate of successful breeding in white-footed mice, it did not appear to affect the pattern of results with all data being in the normal range for this species and similar to the results for the additional colony animals that were used as controls (see Results).

\section{AVP-ir Differences}

We examined species differences in AVP-ir and behavior. We collected behavioral data while each mother was caring for a first litter of pups (described above) in order to correlate these behavioral data with AVP-ir measurements obtained after the birth of a second litter. Parental care data were not available for 2 litters of control white-footed mice. Females had previously been exposed to aggression tests as sexually naïve females at an average of 10 months of age (6 months prior to sacrifice) and as sexually experienced females at an average of 15 months of age (1 month prior to sacrifice). All females were sacrificed between 11:00 and 13:00 by decapitation on the 3rd day after the birth of their second litter of pups using the methods of Bamshad et al. [1994]. To prevent disturbance of the animals, cages remained in the colony room until immediately prior to sacrifice.

Brains were fixed, frozen and sectioned as previously described [Bester-Meredith and Marler, 2003a]. After sectioning, immunohistochemistry for AVP was performed on free-floating sections [Bester-Meredith and Marler, 2001]. Sections were stored overnight in Tris- $\mathrm{NaCl}$ and mounted onto slides, air dried, and coverslipped the following day. Quantification of AVP protein expression using immunohistochemistry has been used in a variety of species, including Peromyscus mice [Bester-Meredith et al., 1999; Bester-Meredith and Marler 2001, 2003a; Lambert et al., 2011], laboratory mice [Murray et al., 2011], rats [e.g. Zhao and Ai, 2011] and prairie voles [e.g. Lonstein et al., 2005]. Using computerized image analysis software, NIH Image 1.61 [Rasband, 1996], the density of AVP-ir in the BNST, medial amygdala, paraven- tricular nucleus and supraoptic nucleus was analyzed [Bamshad et al., 1993; Wang and De Vries, 1993; Bamshad et al., 1994; Wang, 1995; Bester-Meredith et al., 1999; Bester-Meredith and Marler 2001, 2003a]. Measurements of AVP-ir staining were not made in the lateral septum because coronal sections only revealed light AVP-ir (staining was $<1 \%$ ). Previous studies of AVP-ir in Peromyscus mice have revealed similarly low levels of staining in this species [Bester-Meredith et al., 1999; Bester-Meredith and Marler, 2001, 2003a] even after administering colchicine [Bester-Meredith and Marler, unpubl. data]. The density of cells and fibers was expressed as the total area covered by AVP-ir cells and fibers within a sampling area [Bamshad et al., 1993, 1994; Bester-Meredith et al., 1999; Bester-Meredith and Marler, 2001, 2003a]. For each brain area, an observer who was blind to the subject's species and treatment condition traced each brain area bilaterally on the section with maximum percent staining and calculated the percent staining for each brain area. All cells were counted on the section with maximum percent staining and additional measurements of cell size and optical density were made on 10 cells on each side of the section with maximum percent staining. If fewer than 10 cells were present, all were measured.

To examine the effects of cross-fostering on AVP-ir in addition to general species differences in AVP-ir staining, we studied a subset of 32 sexually experienced females obtained from the parental behavior study described above. Eight females, which were on average 16 months old, were taken from each of the following four groups: control white-footed mice, cross-fostered white-footed mice, control California mice and cross-fostered California mice. Brains were assayed in 8 sets of 4 (described below) such that each set included 1 brain from each of the 4 groups for both species. Tissue damage prevented measurement of the medial amygdala and supraoptic nucleus in 1 control white-footed mouse. Data for 1 pair of cross-fostered white-footed mice and 1 pair of control white-footed mice were averaged because the animals were siblings, leading to a final sample size of 8 cross-fostered California mice, 8 control California mice, 7 control white-footed mice ( 6 for measurements in the medial amygdala and supraoptic nucleus) and 6 cross-fostered white-footed mice. Cross-fostered animals were compared with control animals instead of in-fostered animals because there was no significant difference in the time of year that the brains of cross-fostered and control mice were collected $[\mathrm{F}(1,27)=11, \mathrm{p}=0.75]$, whereas there was a difference between cross-fostered and in-fostered mice $[\mathrm{F}(1,27)=10.89, \mathrm{p}=0.003]$, and because maternal behavior measurements revealed no behavioral differences between control and in-fostered mice.

\section{Statistical Analyses}

All statistical analyses were conducted using the computer program Statistica (StatSoft, Inc., Tulsa, Okla., USA). In all studies, we averaged data from individuals from the same biological parents to minimize the effects of parentage. All $\mathrm{p}$ values are based on two-tailed statistical tests. Data are presented as means $\pm \mathrm{SE}$ in the text and figures.

Because the four component variables of HNGI occurred simultaneously and were highly intercorrelated (range of Spearman R: 0.33-0.98) it was necessary to form a composite score (HNGI score) [Bester-Meredith and Marler, 2003b; Bester-Meredith and Marler, 2007]. If we averaged our raw behavioral data for each animal to form a composite score, common behaviors like huddling would be overrepresented in the averaged values in com- 
Fig. 1. Representative photomicrographs of AVP-ir in the BNST comparing control (a) and cross-fostered (b) white-footed mice and control (c) and cross-fostered (d) California mice. Bar $=100 \mu \mathrm{m}$.
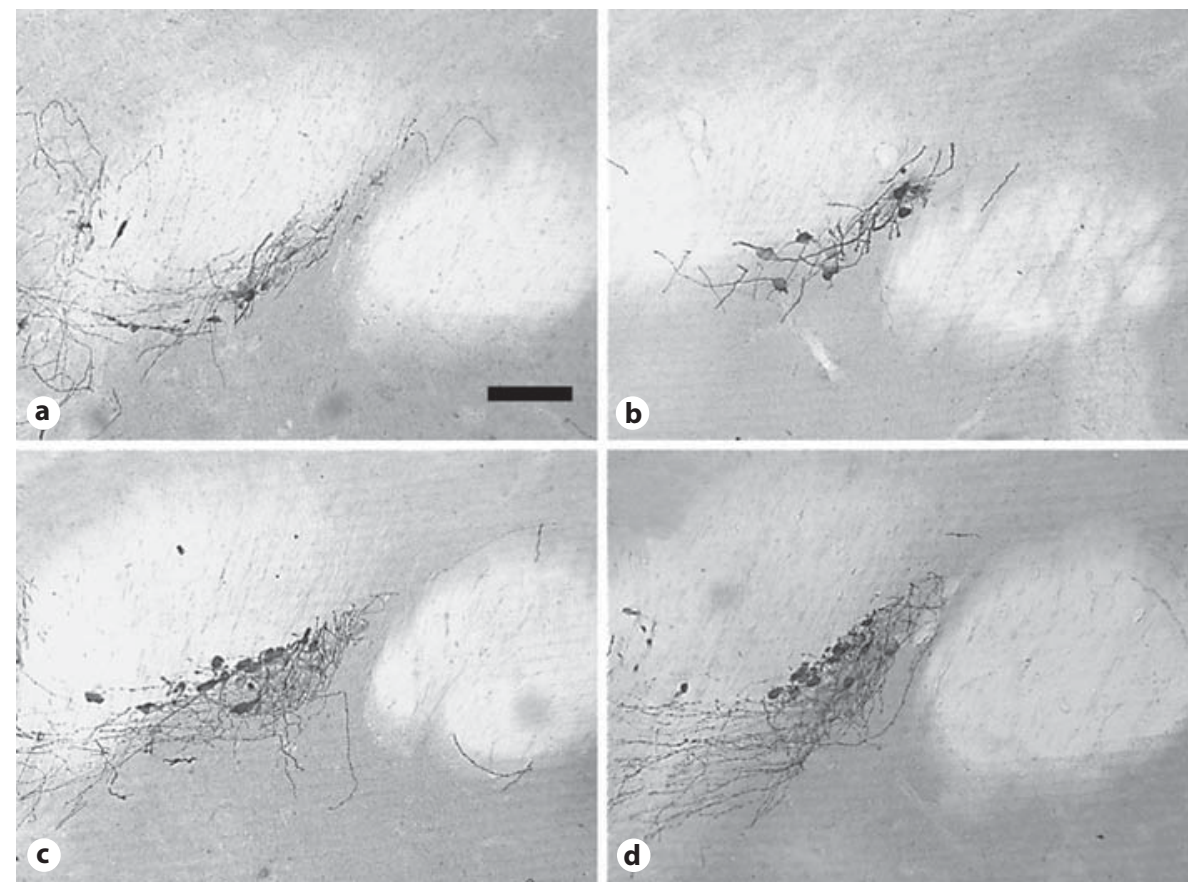

parison to rare behaviors like grooming because all behaviors were measured in seconds. Despite the intercorrelation of the variables, variation in rare behaviors would have little effect on the overall composite score. Therefore, we standardized the scale of each variable using $\mathrm{Z}$-scores because of differences in the central tendency and variability in the amount of time that each behavior was performed. Because Z-scores are normalized scores, they no longer have a unit such as seconds. Averaging these Zscores to form the composite HNGI allowed relatively rare behaviors (such as grooming) and relatively common behaviors (such as huddling) to contribute equally to the score because they showed nearly identical relationships with the dependent variables [Bester-Meredith and Marler, 2003b, 2007]. Mann-Whitney $\mathrm{U}$ tests were used to compare the maternal behavior of the two species and between cross-fostered and in-fostered mice. We also tested whether percent AVP-ir in any of the four brain areas correlated with any of the three measures of parental behavior using Spearman rank-order correlations. Because we performed multiple comparisons, we used the Benjamini-Hochberg procedure to correct $\mathrm{p}$ values within each species [McDonald, 2009].

To examine whether species differences in vasopressin were influenced by cross-fostering, we used analysis of covariance. In this analysis, we examined whether the main effects of fostering group and species could predict maximum percent AVP-ir and used multivariate analysis of variance to analyze cell size, optical density and cell number from the section with maximum percent staining with sibling sex ratio and assay date as covariates [BesterMeredith and Marler, 2001, 2003a]. We examined the effects of cross-fostering within each species by using planned comparisons.

\section{Results}

\section{Species Differences in Maternal Behavior}

Species differences in the HNGI score $(\mathrm{U}=181, \mathrm{Z}=$ 2.33, $\mathrm{p}=0.02)$ and nest building $(\mathrm{U}=164, \mathrm{Z}=-2.67, \mathrm{p}=$ 0.008 ) were found, illustrating the lower level of maternal care in white-footed mice. However, maternal retrievals did not differ between the species $(U=291, Z=-0.12$, $\mathrm{p}=0.90)$.

\section{Maternal Behavior and AVP-ir}

Measurements of AVP-ir also differed between these species, although in fewer areas than expected. In species comparisons of colony control females, California mice showed a higher percentage of AVP-ir than white-footed mice in the BNST $[\mathrm{F}(1,23)=50.32, \mathrm{p}<0.00001]$ and $\mathrm{a}$ non-significant trend toward a higher percentage of AVPir in the paraventricular nucleus $[\mathrm{F}(1,23)=3.31, \mathrm{p}=0.08$; fig. 1, 2]. We observed no species differences in AVP-ir in the medial amygdala or supraoptic nucleus (both $\mathrm{p}>$ 0.30).

Because of the species differences in the HNGI score and AVP, we also explored associations between AVP-ir staining and individual levels of maternal behavior within each species. Within California mice, we found a nonsignificant trend towards the percentage of AVP-ir staining in the medial amygdala of sexually experienced fe- 
male California mice being positively associated with the HNGI score (fig. 3; Spearman $\mathrm{R}=0.63, \mathrm{p}=0.009$; critical $\mathrm{p}$ value using Benjamini-Hochberg correction $=0.008$ ) but not with retrieval or nesting behavior (all $\mathrm{p}>0.23$ ). In contrast, within white-footed mice, the percentage of AVP-ir in the medial amygdala of the sexually experienced female white-footed mice was not associated with any of our behavioral measures (all $\mathrm{p}>0.18$ ). Maternal behaviors were also unrelated to AVP-ir staining in the BNST, paraventricular nucleus and supraoptic nucleus when California mice or white-footed mice were examined independently (all $\mathrm{p}>0.12$ ).

\section{Cross-Fostering and Maternal Behavior}

At the same time as the above studies, we also examined whether there is plasticity in maternal behavior when raised by a species with different levels of maternal behavior. However, none of these behaviors were altered in a comparison of cross-fostered and in-fostered mice (table 2; HNGI score in California mice: $\mathrm{U}=36, \mathrm{Z}=0.40$, $\mathrm{p}=0.69$; HNGI score in white-footed mice: $\mathrm{U}=10, \mathrm{Z}=$ $-1.46, \mathrm{p}=0.14$; nest building in California mice: $\mathrm{U}=39.5$, $\mathrm{Z}=-0.09, \mathrm{p}=0.93$, and nest building in white-footed mice: $\mathrm{U}=18, \mathrm{Z}=0.29, \mathrm{p}=0.77$ ). Maternal retrievals did not differ between cross-fostered and in-fostered mice (table 2; California mice: $U=29, Z=-1.02, p=0.31$; white-footed mice: $U=15, Z=0.73, p=0.46)$. Therefore, we found no evidence that cross-fostering alters maternal behavior.

\section{Cross-Fostering and AVP-ir}

Consistent with the previous lack of behavioral changes in response to cross-fostering and the lack of species differences (apart from the BNST), we also found little evidence for differences in AVP-ir in response to crossfostering for each species individually or when species were combined for all brain areas except for the supraoptic nucleus (fig. 2, 4; all p > 0.09). Although cross-fostering did not alter maximum percent staining in the supraoptic nucleus $[\mathrm{F}(1,22)=0.07, \mathrm{p}=0.80]$, cross-fostering influenced the overall pattern of cell measurements in the supraoptic nucleus [Wilks' $\lambda(3,20)=0.63, p=0.02$ ]. Further analysis showed that this overall change in cell measurements was caused by a decrease in cell area only in California mice $[\mathrm{F}(1,22)=6.99, \mathrm{p}=0.01]$ but no change in cell number or optical density or in any of the measures in white-footed mice (all $\mathrm{p}>0.14$ ). The function of this decrease is unclear. Overall, cross-fostering did not alter AVP-ir in a consistent way in any brain area or in a manner that suggested that they were becoming more similar to their foster parents.

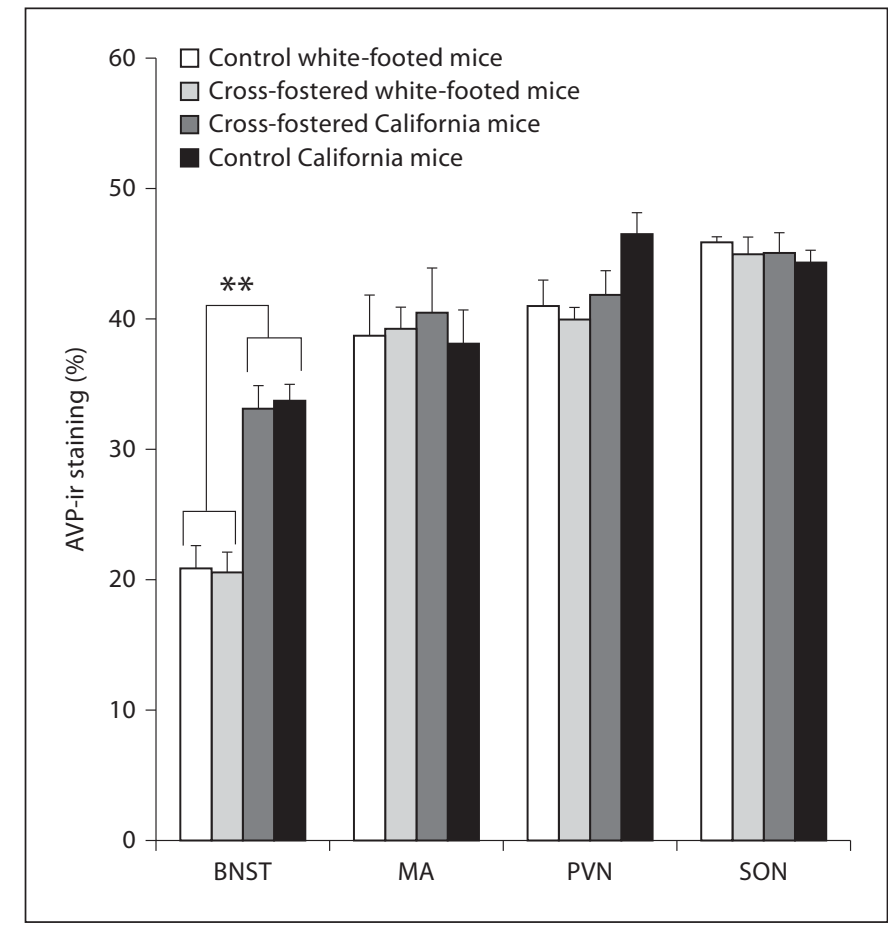

Fig. 2. Despite a statistically significant species difference in AVPir in the BNST $[\mathrm{F}(1,23)=50.32, \mathrm{p}<0.00001]$, cross-fostering did not alter AVP-ir in the BNST, medial amygdala (MA), paraventricular nucleus of the hypothalamus (PVN) or the supraoptic nucleus (SON) in sexually experienced female white-footed mice or California mice. $\mathrm{n}=8$ per group for cross-fostered California mice and control California mice, $\mathrm{n}=7$ for control white-footed mice ( 6 for measurements in the MA and SON), and $n=6$ for cross-fostered white-footed mice. ${ }^{* *} \mathrm{p}<0.00001$.

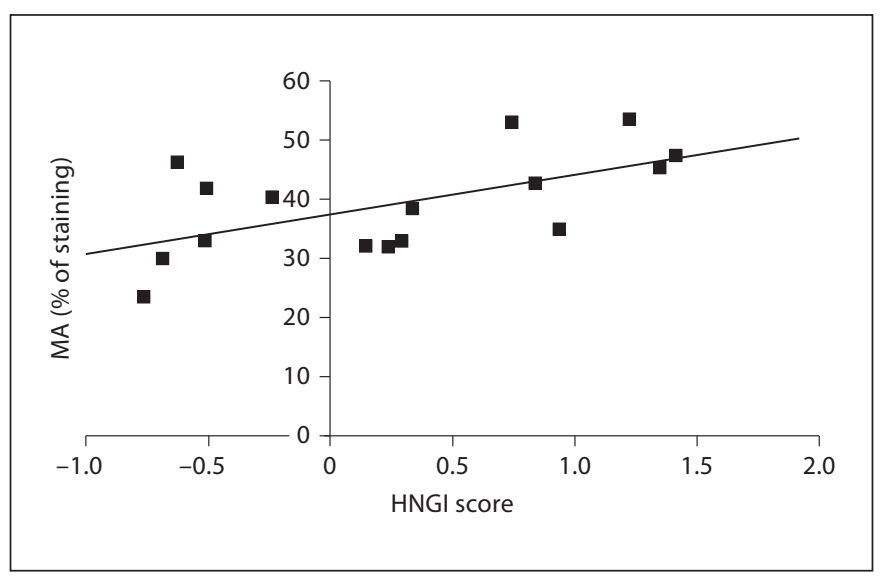

Fig. 3. The HNGI score is positively associated with the percentage of AVP-ir in the medial amygdala (MA) in the same sexually experienced female California mice $(-\mathbf{\square}-\mathrm{n}=16)$. Spearman $\mathrm{R}=0.63, \mathrm{p}=0.009$, critical $\mathrm{p}$ value using Benjamini-Hochberg correction $=0.008$.

Brain Behav Evol 2012;80:244-253 


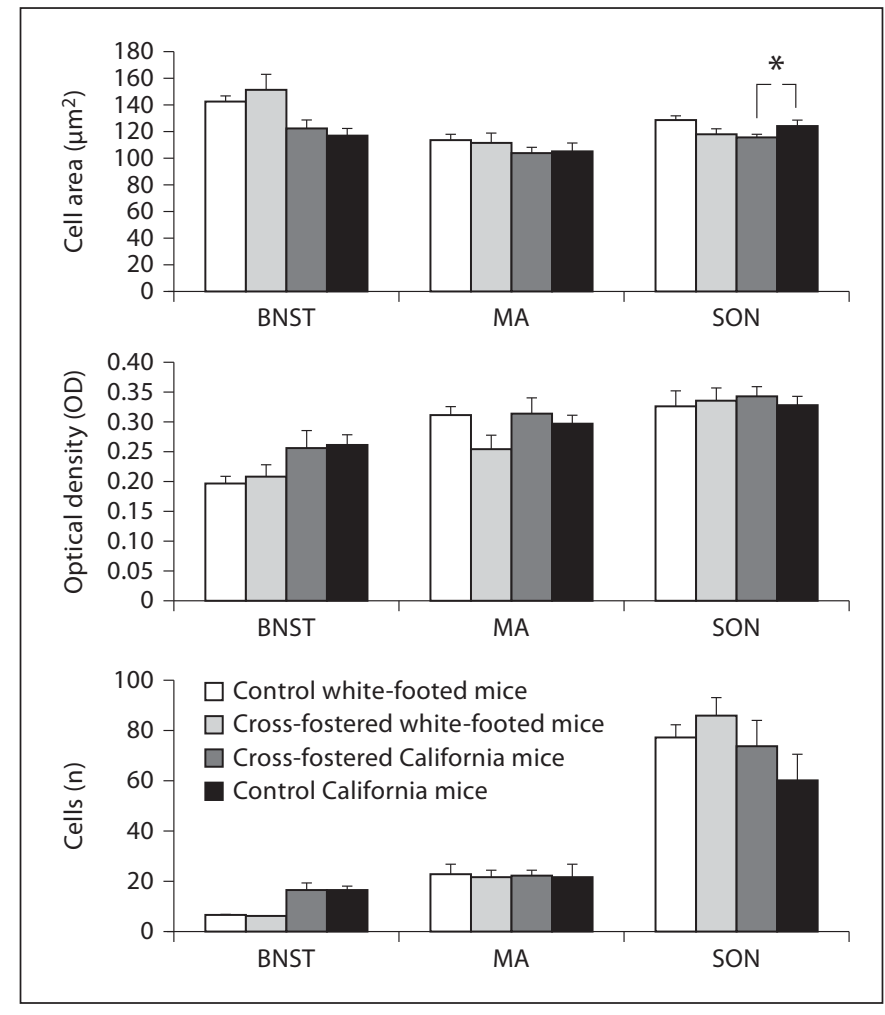

Fig. 4. Cross-fostering did not alter the area, optical density and number of AVP-ir neurons in the BNST, medial amygdala (MA), paraventricular nucleus of the hypothalamus (PVN) or the supraoptic nucleus (SON) in sexually experienced female white-footed mice or California mice. However, cell number differs in the SON only in California mice [Wilks' $\lambda(3,20)=0.63, \mathrm{p}=0.02$ ]. $\mathrm{n}=8$ per group for cross-fostered California mice and control California mice, $\mathrm{n}=7$ for control white-footed mice ( 6 for measurements in the MA and SON), and $n=6$ for cross-fostered white-footed mice. ${ }^{*} \mathrm{p}=0.02$.

\section{Discussion}

\section{Differences between Species}

California mice and white-footed mice differ significantly in maternal care. However, the disparity in maternal behavior shown by these two species is smaller than our previously described differences in male paternal behavior [Bester-Meredith et al., 1999]. This finding indicates that white-footed mouse pups receive less parental care from both parents. In contrast to California mice, which tend to have 1-3 large pups, white-footed mice more closely resemble R-selected species with larger numbers of smaller and less-developed pups. Although there were few species differences in AVP-ir, we found higher AVP-ir in female California mice in the BNST. This raises the hypothesis that AVP is associated with higher levels of maternal behavior. Interestingly, a similar relationship was found in male Peromyscus mice, although with pup retrievals and not other measures of paternal behavior [Bester-Meredith and Marler, 2003a]. Data in another closely related species, Peromyscus maniculatus, indicate that AVP in the BNST may be important in the transition to paternal care [Lambert et al., 2011].

Species differences in vasopressin may be related to species differences in parental behavior, although several other scenarios for a broader function of AVP in these brain areas are also plausible because of the involvement of AVP in such a variety of social processes. Previous studies have suggested that AVP regulates a plethora of types of social behavior across species, including parental behavior, aggression, pair bonding [reviewed by Caldwell et al., 2008] and copulation [Ho et al., 2010]. In California mice spe-

Table 2. Maternal behavior of Peromyscus mice reared by biological (control) or foster parents

\begin{tabular}{|c|c|c|c|c|c|c|}
\hline & $\begin{array}{l}\text { Retrieving } \\
\text { pups }\end{array}$ & Nest building & \multicolumn{4}{|c|}{ Components of the HNGI score } \\
\hline Control & $3.4 \pm 1.6$ & $24.0 \pm 9.3^{\mathrm{a}}$ & $562.9 \pm 149.6^{\mathrm{b}}$ & $511.9 \pm 154.7^{\mathrm{b}}$ & $11.2 \pm 3.5^{\mathrm{b}}$ & $589.1 \pm 154.1^{\mathrm{b}}$ \\
\hline In-fostered & $5.8 \pm 4.0$ & $59.2 \pm 49.3^{\mathrm{a}}$ & $610.5 \pm 142.9^{b}$ & $502.8 \pm 150.3^{\mathrm{b}}$ & $21.5 \pm 10.0^{\mathrm{b}}$ & $622.8 \pm 131.6^{\mathrm{b}}$ \\
\hline Cross-fostered & $5.7 \pm 1.7$ & $63.1 \pm 44.3^{\mathrm{a}}$ & $358.1 \pm 78.7^{\mathrm{b}}$ & $293.8 \pm 76.3^{\mathrm{b}}$ & $32.1 \pm 15.5^{\mathrm{b}}$ & $429.1 \pm 67.3^{\mathrm{b}}$ \\
\hline In-fostered & $15.3 \pm 8.4$ & $5.5 \pm 3.8^{c}$ & $530.9 \pm 58.0^{\mathrm{d}}$ & $501.1 \pm 55.5^{\mathrm{d}}$ & $98.5 \pm 14.6^{\mathrm{d}}$ & $596.2 \pm 66.6^{\mathrm{d}}$ \\
\hline Cross-fostered & $4.1 \pm 2.3$ & $4.7 \pm 3.4^{\mathrm{c}}$ & $647.3 \pm 95.9^{d}$ & $566.3 \pm 81.9^{\mathrm{d}}$ & $95.8 \pm 15.0^{\mathrm{d}}$ & $655.5 \pm 82.5^{\mathrm{d}}$ \\
\hline $\begin{array}{l}\text { All data are pre } \\
\text { into its four com } 1 \\
\text { means } \pm \text { SE. Cor } \\
\text { and in-fostered ani }\end{array}$ & $\begin{array}{l}\text { seconds } \\
\text { ariables. } \\
\text { s were } \mathrm{m} \\
\text { between }\end{array}$ & $\begin{array}{l}\text { JGI score is } \\
\text { e presented } \\
\text { ween cross- } f \\
\text { red and cont }\end{array}$ & \multicolumn{4}{|c|}{$\begin{array}{l}\text { mals. Despite species differences in the HNGI score (labeled with } \\
\text { superscripts b and } d ; U=181, Z=2.33, p=0.02 \text { ) and nest building } \\
\text { (labeled with superscripts a and } c ; U=164, Z=-2.67, p=0.008 \text { ), } \\
\text { cross-fostering did not affect maternal behavior. }\end{array}$} \\
\hline
\end{tabular}


cifically, AVP in the BNST has been associated with male paternal care [Bester-Meredith and Marler, 2003a] (but see de Jong et al. [2009], in which males were tested with unfamiliar pups and undisturbed observations were not used) and male-male aggression [Bester-Meredith and Marler, 2001; Bester-Meredith et al., 2005; Frazier et al., 2006]. There is even less information regarding the effect of AVP on female social behavior in Peromyscus mice. Recent studies have implicated AVP as regulating broader phenomena such as maternal anxiety [Bosch, 2011], maternal memory [Nephew and Bridges, 2008b] or other social/ affiliative memory [reviewed by Caldwell et al., 2008], but none of these studies have been conducted in Peromyscus.

Our data both provide a link between AVP and maternal behavior and are also consistent with the idea of at least limited overlap between the sexes in the functioning of AVP and oxytocin. AVP and oxytocin influence pair bonding in both sexes [Cho et al., 1999; Liu et al., 2001]. Oxytocin and vasopressin pathways also appear to interact with each other at the physiological level, including binding to both types of receptors [reviewed by Raggenbass, 2008]. These interactions also seem to have behavioral effects, although they are not completely understood [Bales et al., 2004; Kramer et al., 2006; Pedersen and Boccia, 2006; Bales et al., 2007; reviewed by Bosch and Neumann, 2012].

\section{Associations between Maternal Behavior and AVP within Each Species}

Within California mice, but not white-footed mice, we found a non-significant trend towards a positive association between the HNGI score and the percentage of AVP-ir in the medial amygdala of the sexually experienced female California mice. Because white-footed mice show less maternal behavior and AVP-ir than California mice, this association may be absent due to the smaller range of values for both variables for this species. This study provides one of the first associations between levels of naturally produced AVP-ir protein in the medial amygdala and the level of maternal behavior represented by the HNGI score. The role of the medial amygdala in regulating maternal behavior may be closely related to the information that it receives from the olfactory system, which in turn influences the level of fearfulness in rats towards pups [Walsh et al., 1996]. This study is important because previous research has revealed positive links between AVP and maternal care in rats using AVP manipulations [Pedersen et al., 1982, 1994; Nephew and Bridges, 2008a; Kessler et al., 2011], but less is known about the role of naturally occurring vasopressin in regulating maternal behavior.
Absence of Flexibility in the Development of Maternal Behavior and Vasopressin

In contrast to previous findings in males [Bester-Meredith and Marler, 2003a], manipulations of the postnatal social environment did not alter maternal behavior. This finding is perhaps surprising considering that female California mice are capable of displaying flexibility in maternal behavior as adults. When female California mice are pair bonded with males displaying less huddling behavior towards pups (via castration), the females partially compensate by expressing increased huddling behavior [Trainor and Marler, 2001]. Female rats also show flexibility in the amount of care provided to offspring in response to experience during development, including reduced adult maternal licking and crouching over pups after maternal separation [Lovic et al., 2001]. The effect of maternal licking can continue across generations because both biological and foster female offspring of low licking and grooming females tend to show similarly low levels of licking and grooming when raising their own offspring [Francis et al., 1999]. In the current study, less pronounced difference in maternal care between the two species compared to the differences found in paternal care [Bester-Meredith et al., 1999; Marler et al., 2003, 2008] may limit our ability to identify similar patterns of cross-generational changes.

The stability of AVP production also differed between males and females. In comparison to our previous findings in males [Bester-Meredith and Marler, 2001], AVP production remained stable after cross-fostering in females. There are likely several reasons for this, but two primary possibilities are (1) that AVP in the brain areas measured is not related to maternal behavior and (2) that species differences in maternal behavior may depend more on genetic variation. Our findings that individual variation in maternal behavior is associated with AVP-ir supports the latter possibility. Although there is considerable intraspecies variation in maternal care, this large variation does not preclude cross-fostering effects on parental behavior because we previously found associations between AVP and male parental care despite similarly high intraspecific variation in paternal behavior [BesterMeredith and Marler, 2003a]. An additional possibility is that the low sensitivity of immunohistochemistry in comparison to other techniques such as Western blots may also have limited our ability to detect more subtle differences in AVP. 


\section{Conclusions}

Female Peromyscus mice show a species difference in maternal behavior that is associated with a species difference in AVP-ir in the BNST. Male Peromyscus share this association, but also show a positive association between the HNGI/HGI scores and AVP-ir in the BNST [BesterMeredith and Marler, 2003a]. Female California mice show a similar positive relationship between the HNGI score and AVP-ir staining in the medial amygdala. These results indicate that although AVP has been associated primarily with the regulation of paternal behavior, it may also be important in regulating maternal behavior in certain species. Therefore, dysregulation of AVP pathways might serve as a physiological basis for abnormalities in maternal behavior as well as in paternal behavior. Overall, we have identified potentially important functions for AVP in the regulation of maternal behavior in females.

\section{Acknowledgments}

The research presented here was described in Animal Research Protocol A-48-7400-L00221-3-01-98 and approved on February 26, 1998, by the University of Wisconsin Research Animal Resource Committee. We thank P.A. Martin, C.W. Meredith, K. Theusch, N.M. Ingrisano, R.A. Zurawski, S.J. Enters, T.K. Haag, K. Berrall, S.P. Hartl, G. Polite, S. Aggar and T. Aggar for technical assistance. We thank P.A. Martin, E. Becker, M. Fuxjager and J. Pultorak for valuable feedback on the manuscript. This research was supported by a NRSA Predoctoral Fellowship F31 MH12287, a Vilas Professional Development Award, and a Vilas Graduate Fellowship to J.K.B.-M. and grant IOB-0620042 to C.A.M.

\section{References}

Bales KL, Kim AJ, Lewis-Reese AD, Carter CS Bester-Meredith JK, Marler CA (2003b): The as(2004): Both oxytocin and vasopressin may influence alloparental behavior in male prairie voles. Horm Behav 45:354-361.

Bales KL, Plotsky PM, Young LJ, Lim MM, Grotte N, Ferrer E, Carter CS (2007): Neonatal oxytocin manipulations have long-lasting, sexually dimorphic effects on vasopressin receptors. Neuroscience 144:38-45.

Bamshad M, Novak MA, De Vries GJ (1993): Sex and species differences in the vasopressin innervation of sexually naive and parental prairie voles, Microtus ochrogaster and meadow voles, Microtus pennsylvanicus. J Neuroendocrinol 5:247-255.

- Bamshad M, Novak MA, De Vries GJ (1994): Cohabitation alters vasopressin innervation and paternal behavior in prairie voles $(\mathrm{Mi}$ crotus ochrogaster). Physiol Behav 56:751758.

Beiderbeck DI, Neumann ID, Veenema AH (2007): Differences in intermale aggression are accompanied by opposite vasopressin release patterns within the septum in rats bred for low and high anxiety. Eur J Neurosci 26: 3597-3605.

- Bester-Meredith JK, Marler CA (2001): Vasopressin and aggression in cross-fostered California mice (Peromyscus californicus) and white-footed mice (Peromyscus leucopus). Horm Behav 40:51-64.

Bester-Meredith JK, Marler CA (2003a): Vasopressin and the transmission of paternal behavior across generations in mated crossfostered Peromyscus mice. Behav Neurosci 117:455-463. sociation between male offspring aggression and paternal and maternal behavior of Peromyscus mice. Ethology 109:797-808.

ester-Meredith JK, Marler CA (2007): Social experience during development and female offspring aggression in Peromyscus mice. Ethology 113:889-900.

-Bester-Meredith JK, Martin PA, Marler CA (2005): Manipulations of vasopressin alter aggression differently across testing conditions in monogamous and non-monogamous Peromyscus mice. Aggress Behav 31: 189-199.

Bester-Meredith JK, Young LJ, Marler CA (1999): Species differences in paternal behavior and aggression in Peromyscus and their associations with vasopressin immunoreactivity and receptors. Horm Behav 36:25-38.

Bosch OJ (2011): Maternal nurturing is dependent on her innate anxiety: the behavioral roles of brain oxytocin and vasopressin. Horm Behav 59:202-212.

Bosch OJ, Neumann ID (2012): Both oxytocin and vasopressin are mediators of maternal care and aggression in rodents: From central release to sites of action. Horm Behav 61: 293-303.

Caldwell HK, Lee H-J, Macbeth AH, Young WS 3rd (2008): Vasopressin: behavioral roles of an 'original' neuropeptide. Prog Neurobiol 84:1-24.

Cho MM, DeVries AC, Williams JR, Carter CS (1999): The effects of oxytocin and vasopressin on partner preferences in male and female prairie voles (Microtus ochrogaster). Behav Neurosci 113:1071-1079.
Dantzer R, Koob GF, Bluthe RM, LeMoal M (1988): Septal vasopressin modulates social memory in male rats. Brain Res 457:143-147. de Jong TR, Chauke M, Harris BN, Saltzman W (2009): From here to paternity: neural correlates of the onset of paternal behavior in California mice (Peromyscus californicus). Horm Behav 56:220-231.

Engelmann M, Landgraf R (1994): Microdialysis administration of vasopressin into the septum improves social recognition in Brattleboro rats. Physiol Behav 55:145-149.

Ferris CF, Melloni RH Jr, Koppel G, Perry KW, Fuller RW, Delville Y (1997): Vasopressin/serotonin interactions in the anterior hypothalamus control aggressive behavior in golden hamsters. J Neurosci 17:4331-4340.

-Francis D, Diorio J, Liu D, Meaney MJ (1999): Nongenomic transmission across generations of maternal behavior and stress responses in the rat. Science 286:1155-1158.

- Frazier CRM, Trainor BC, Cravens CJ, Whitney TK, Marler CA (2006): Paternal behavior influences development of aggression and vasopressin expression in male California mouse offspring. Horm Behav 50:699-707.

Gonzalez-Mariscal G, Chirino R, Rosenblatt JS, Beyer C (2005): Forebrain implants of estradiol stimulate maternal nest-building in ovariectomized rabbits. Horm Behav 47: 272-279.

Gubernick DJ, Alberts JR (1987): The biparental care system of the California mouse, Peromyscus californicus. J Comp Psychol 101: 169-177. 
-Gubernick DJ, Alberts JR (1989): Postpartum maintenance of paternal behavior in the biparental California mouse, Peromyscus californicus. Anim Behav 37:656-664.

Gubernick DJ, Teferi T (2000): Adaptive significance of male parental care in a monogamous mammal. Proc R Soc Lond B Biol Sci 267:147-150.

Gubernick DJ, Wright S, Brown RE (1993): The significance of father's presence for offspring survival in the monogamous California mouse, Peromyscus californicus. Anim Behav 46:539-546.

- Ho JM, Murray JH, Demas GE, Goodson JL (2010): Vasopressin cell groups exhibit strongly divergent responses to copulation and male-male interactions in mice. Horm Behav 58:368-377.

- Kessler MS, Bosch OJ, Bunck M, Landgraf R, Neumann ID (2011): Maternal care differs in mice bred for high vs. low trait anxiety: impact of brain vasopressin and cross-fostering. Social Neurosci 6:156-168.

Keverne RB, Curley JP (2004): Vasopressin, oxytocin, and social behavior. Curr Opin Neurobiol 14:777-783.

-Kramer KM, Choe C, Carter CS, Cushing BS (2006): Developmental effects of oxytocin on neural activation and neuropeptide release in response to social stimuli. Horm Behav 49: 206-214.

-Lambert KG, Franssen CL, Bardi M, Hampton JE, Hainley L, Karsner S, Tu EB, Hyer MM, Crockett A, Baranova A, Ferguson T, Ferguson T, Kinsley CH (2011): Characteristic neurobiological patterns differentiate paternal responsiveness in two Peromyscus species. Brain Behav Evol 77:159-175.

- Liu Y, Thomas CJ, Wang Z (2001): Vasopressin in the lateral septum regulates pair bond formation in male prairie voles (Microtus ochrogaster). Behav Neurosci 115:910-919.

Lonstein JS, Rood BD, De Vries GJ (2005): Unexpected effects of perinatal gonadal hormone manipulations on sexual differentiation of the extrahypothalamic arginine-vasopressin system in prairie voles. Endocrinology 146:1559-1567.

Lovic V, Gonzalez A, Fleming AS (2001): Maternally separated rats show deficits in maternal care in adulthood. Dev Psychobiol 39:19-33.

- Lukas M, Bredewold R, Landgraf R, Neumann ID, Veenema AH (2011): Early life stress impairs social recognition due to a blunted response of vasopressin release within the septum of male rats. Psychoneuroendocrinology $36: 843-853$.

-Ma X, Lightman SL, Aguilera G (1999): Vasopressin and corticotropin-releasing hormone gene responses to novel stress in rats adapted to repeated restraint. Endocrinology 140:3623-3632.
Mann PE, Bridges RS (2002): Prolactin receptor gene expression in the forebrain of pregnant and lactating rats. Mol Brain Res 105:136145.

Marler CA, Bester-Meredith JK, Trainor BC (2003): Paternal behavior and aggression: endocrine mechanisms and nongenomic transmission of behavior; in Slater PJB, Rosenblatt JS, Snowdon CT, Roper TJ (eds): Advances in the Study of Behavior. New York, Academic Press, vol 32, pp 263-323.

Marler CA, Trainor BC, Gleason ED, BesterMeredith JK, Becker EA (2008): The effects of paternal behavior on offspring aggression and hormones in the biparental California mouse; in Bridges RS (ed): Neurobiology of the Parental Brain. New York, Elsevier, pp 435-448.

McDonald JH (2009): Handbook of Biological Statistics, ed 2. Baltimore, Sparky House Publishing, pp 256-259.

- Murray EK, Varnum MM, Fernandez JL, de Vries GJ, Forger NG (2011): Effects of neonatal treatment with valproic acid on vasopressin immunoreactivity and olfactory behaviour in mice. J Neuroendocrinol 23:906-914.

-Nephew BC, Bridges RS (2008a): Central actions of arginine vasopressin and a V1a receptor antagonist on maternal aggression, maternal behavior, and grooming in lactating rats. Pharmacol Biochem Behav 91:77-83.

Nephew BC, Bridges RS (2008b): Arginine vasopressin $V 1$ a receptor antagonist impairs maternal memory in rats. Physiol Behav 95:182186.

Parker KJ, Lee TM (2001): Central vasopressin administration regulates the onset of facultative paternal behavior in Microtus pennsylvanicus (meadow voles). Horm Behav 39: 285-294.

- Pedersen CA, Ascher JA, Monroe YL, Prange AJ $\operatorname{Jr}$ (1982): Oxytocin induces maternal behavior in virgin female rats. Science 216:648650.

Pedersen CA, Boccia ML (2006): Vasopressin interactions with oxytocin in the control of female sexual behavior. Neurosci 139:843851.

Pedersen CA, Caldwell JD, Walker C, Ayers G, Mason GA (1994): Oxytocin activates the postpartum onset of rat maternal behavior in the ventral tegmental and medial preoptic areas. Behav Neurosci 108:1163-1171.

- Raggenbass M (2008): Overview of cellular electrophysiological actions of vasopressin. Eur J Pharmacol 583:243-254.

Rasband W (1996): NIH Image [Computer Software]. Bethesda, National Institutes of Health.
Ribble DO (1991): The monogamous mating system of Peromyscus californicus as revealed by DNA fingerprinting. Behav Ecol Sociobiol 29:161-166.

Ruscio MG, Adkins-Regan E (2004): Immediate early gene expression associated with induction of brooding behavior in Japanese quail. Horm Behav 46:19-29.

Schug MD, Vessey SH, Underwood EM (1992): Paternal behavior in a natural population of white-footed mice (Peromyscus leucopus). Am Midl Nat 127:373-380.

Scott V, Brown CH (2010): State-dependent plasticity in vasopressin neurones: dehydrationinduced changes in activity patterning. J Neuroendocrinol 22:343-354.

Trainor BC, Marler CA (2001): Testosterone, paternal behavior, and aggression in the monogamous California mouse (Peromyscus californicus). Horm Behav 40:32-42.

- Vega C, Moreno-Carranza B, Zamorano M, Quintanar-Stéphano A, Méndez I, Thebault S, Martínez de la Escalera G, Clapp C (2010): Prolactin promotes oxytocin and vasopressin release by activating neuronal nitric oxide synthase in the supraoptic and paraventricular nuclei. Am J Physiol Regul Integr Comp Physiol 299:R1701-R1708.

Walsh CJ, Fleming AS, Lee A, Magnusson JE (1996): The effects of olfactory and somatosensory desensitization on Fos-like immunoreactivity in the brains of pup-exposed postpartum rats. Behav Neurosci 110:134153.

Wang Z (1995): Species differences in the vasopressin-immunoreactive pathways in the bed nucleus of the stria terminalis and the medial amygdaloid nucleus in prairie voles (Microtus ochrogaster) and meadow voles (Microtus pennsylvanicus). Behav Neurosci 109:305-311.

-Wang Z, De Vries GJ (1993): Testosterone effects on paternal behavior and vasopressin immunoreactive projections in prairie voles ( $\mathrm{Mi}$ crotus ochrogaster). Brain Res 631:156-160.

Wang Z, Ferris CF, De Vries GJ (1994): Role of septal vasopressin innervation in paternal behavior in prairie voles (Microtus ochrogaster). Proc Natl Acad Sci 91:400-404.

Wotjak CT, Kubota M, Liebsch G, Montkowski A, Holsboer F, Neumann I, Landgraf R (1996): Release of vasopressin within the rat paraventricular nucleus in response to emotional stress: a novel mechanism of regulating adrenocorticotropic hormone secretion? J Neurosci 16:7725-7732.

Zhao D-Q, Ai H-B (2011): Oxytocin and vasopressin involved in restraint water-immersion stress mediated by oxytocin receptor and vasopressin $1 \mathrm{~b}$ receptor in rat brain. PLoS One 6:1-11. 